\title{
Negociando gênero em desenvolvimento: os feminismos brasileiros em destaque*
}

Cecilia Sardenberg**

\begin{abstract}
Resumo
Neste artigo, busco retraçar caminhos e embates enfrentados por feministas na introdução de uma perspectiva de gênero em questões de desenvolvimento, com destaque para as conferências das Nações Unidas (ONU), bem como para as críticas mais recentes ao seu uso nas reuniões de Beijing $+(5,10,15$ e 20). Em especial, procuro retraçar a participação do Brasil nesses embates e refletir sobre retrocessos na nossa política internacional nesse campo com o golpe de 2016.
\end{abstract}

Palavras-chave: Gênero e Desenvolvimento, Conferências da $\mathrm{ONU}$, Beijing +, Feminismos Brasileiros.

\footnotetext{
" Recebido em 16 de outubro de 2017, aceito em 02 de outubro de 2018. Agradeço ao CNPq pela concessão de uma Bolsa de Produtividade (2013-2016) e de Auxílio Pesquisa (2010-2012), bem como ao Pathways of Women's Empowerment Research Programme, vinculado ao Institute of Development Studies-IDS, da Inglaterra, que tornaram possível a pesquisa na qual se baseia este trabalho. Agradeço também à relevante participação de Carla Gisele Batista, responsável pelas entrevistas com feministas brasileiras, e à Maria Helena Guimarães e Sheila Rodriguez pelas transcrições.

** Professora de Antropologia, Universidade Federal da Bahia (UFBA), Salvador, BA, Brasil. ceciliasard@gmail.com
} 
Negotiating Gender in Development:

Brazilian Feminisms Take Center Stage

\begin{abstract}
In this article I retrace some paths and disputes faced by feminists in negotiating the introduction of a gender perspective in development issues, with a focus on UN conferences as well as on the more recent critiques to the inclusion of gender in the Beijing $+(5,10,15$ and 20$)$ meetings. I seek to retrace, in particular, Brazil's participation in these disputes and the setbacks in our international policies in this field since the 2016 coup.
\end{abstract}

Keywords: Gender and Development, UN Conferences, Beijing + , Brazilian Feminisms. 


\section{Introdução}

As investidas feministas pela adoção de uma perspectiva de equidade de gênero nos discursos e práticas relativas a desenvolvimento vêm de longa data. No plano internacional, essas negociações vêm acontecendo desde a criação da Organização das Nações Unidas (ONU), com uma participação destacada dos feminismos brasileiros. Marcamos presença desde a primeira reunião articuladora da ONU, em 1945, quando Bertha Lutz sufragista brasileira de renome - foi uma das quatro mulheres dentre os 160 delegados presentes (Soihet, 2006). Essas companheiras introduziram a igualdade de gênero na carta fundante da ONU, que passou a afirmar, no seu preâmbulo, "[...] fé nos direitos humanos fundamentais, na dignidade e no valor da pessoa humana, e na igualdade de direitos do homem e da mulher assim como das nações grandes e pequenas" (United Nations, 1945:02). ${ }^{1}$ Elas contribuíram também para a criação, em 1946, da Comissão da Condição da Mulher (CSW), como órgão permanente do Conselho Social e Econômico (ECOSOC) da ONU, responsável pela coordenação dos trabalhos de formulação e monitoramento dos planos, plataformas e declarações referentes aos direitos das mulheres no mundo (Bruce, 1998; Jain, 2005; Haddad, 2007; Haddad Guarnieri, 2010; Nicodemos, 2005). ${ }^{2}$

Desde então, tem-se registrado várias tentativas de ajustar programas de desenvolvimento com base na crítica feminista, não havendo, porém, uma visão única, tampouco uma prática uniforme, na adoção da perspectiva de gênero nesses contextos (Cornwall; Harrison; Whitehead, 2007; Cornwall, 2007; Goetz; Sandler,

\footnotetext{
1 No original, em inglês, se lê: "[...] to reaffirm faith in fundamental human rights, in the dignity and worth of the human person, in the equal rights of men and women and of nations large and small [...]." Todas as traduções de textos em língua estrangeira são de minha responsabilidade.

2 A Commission on the Status of Women (CSW) é o principal órgão global voltado para a formulação de políticas de promoção das mulheres e da igualdade de gênero, sendo responsável também pela organização das Conferências Mundiais das Mulheres.
} 
2007). Ademais, esse processo não tem encontrado ampla aceitação dentre os países-membros da ONU, órgão cujos diferentes institutos e fundos, ao lado do Banco Mundial e outras organizações internacionais de cooperação, tem operado no contexto do desenvolvimento social e econômico em termos globais.

Por certo, houve avanços importantes nesse sentido, mas a perspectiva de gênero continua a ser contestada pelos países mais conservadores. Essa pressão contrária foi forte na IV Conferência Mundial da Mulher (IV CMM), realizada em Beijing, China, em 1995, quando foi aprovada a Plataforma de Ação, mantendo-se assim também na série de conferências de Beijing $+(+5,+10$, +15 e +20 ). Em cada uma dessas conferências a perspectiva de gênero precisou ser novamente negociada, tornando-se cada vez mais difícil fazê-lo na medida em que o conservadorismo capitalista patriarcal, aliado às investidas dos diferentes fundamentalismos religiosos, ganha maior espaço no mundo globalizado (Franco, 2003; Molyneux, 2007).

Minhas considerações neste trabalho se voltam para alguns dos caminhos traçados nessas negociações no contexto das conferências da ONU em questão. Em especial, procuro aqui discutir a relevante participação dos feminismos brasileiros nesses espaços, com destaque para a aprovação da Plataforma de Ação e seus desdobramentos nas conferências de Beijing +. Para tanto, baseio-me em pesquisa documental, bem como em entrevistas com feministas brasileiras que participaram desses processos, além de trabalho de campo realizado durante reuniões da CSW, em Nova Iorque, como integrante de delegações brasileiras. ${ }^{3}$

3 No decorrer deste projeto, participei como assessora na delegação brasileira nas seguintes sessões da CSW/ONU, realizadas em N. Iorque: 52 ${ }^{\mathrm{a}}$ (25/02 a 07/03/2008), delegação presidida pela Exma. Ministra Nilcéa Freire; $53^{\mathrm{a}}$ (02 a 15/03/2009), delegação presidida pela Profa. Dra. Lourdes Bandeira, assessora especial da ministra; 54 ${ }^{\mathrm{a}}$ (01 a 12/03/2010, a conferência de Beijing+15), delegação presidida pela Exma. Ministra Iriny Lopes; 55ª (22/02 a 04/03/2011); 56 (27/02 a 05/03/2012), delegação presidida pela Exma. Ministra Eleonora Menicucci; e a 59 ${ }^{a}$ Sessão, em que se realizou a conferência de Beijing +20 (09 a 20/03/2015), delegação presidida pela vice-Ministra, Linda Goulart. Durante 
Note-se que, apesar de nossa mencionada contribuição inicial com a participação de Bertha Lutz, até a década de 1990 o Brasil não se destacou por uma posição mais progressista no tocante aos direitos das mulheres na ONU (Nicodemos, 2005). O regime militar defendeu a ordem patriarcal dominante, sustentando uma postura de "conta gotas" (trickle-down) no tocante à situação das mulheres, argumentando que ela acompanharia o desenvolvimento econômico do país. O Brasil permaneceu alinhado com o G-77, o grupo de nações em desenvolvimento criado dentro da ONU em 1964 para promover os interesses dos países do Sul. ${ }^{4}$ Embora importante na defesa dessas economias, o G-77 manteve-se bastante conservador no tocante às questões de igualdade de gênero e empoderamento de mulheres (Nicodemos, 2005). Somente a partir das conferências mundiais da ONU realizadas na década de 1990, a atuação do Brasil começou a se destacar nesses espaços globais, tendo por trás um intensivo ativismo feminista.

Com efeito, os feminismos brasileiros são hoje reconhecidos mundialmente como uns dos movimentos de mulheres mais diversificados, melhor articulados e mais influentes da América Latina (Sternbach et alii, 1992), tendo avançado para além das nossas fronteiras, com presença marcante nesses espaços globais. Essa atuação foi incisiva na IV CMM e na série de conferências de Beijing + , principalmente, Beijing +10 , Beijing +15 e Beijing +20 , realizadas entre 2005 e 2015, período em que a Secretaria de Políticas para Mulheres (SPM), criada durante o Governo Lula, definiu uma orientação progressista para a atuação da Missão Brasileira na ONU em prol da manutenção dos acordos de Beijing. Contudo, com o golpe de Estado de 2016, afastando a Presidenta Dilma Rousseff do poder $e$ instalando um governo

essas reuniões, participei das atividades da delegação, acompanhando as referidas ministras e representantes e realizando entrevistas com demais membros da delegação brasileira e de outras delegações e representantes de órgãos da ONU.

${ }^{4}$ Sobre o G77, veja-se: http://www.g77.org/doc/ 
retrógado, patriarcal, que não respeita os princípios dos direitos humanos consagrados na ONU, nossa atuação nesses espaços vêse comprometida, acompanhando outros retrocessos na nossa política internacional. O que poderemos esperar?

Para contemplar essas questões neste artigo, inicio com uma discussão sobre modelos de desenvolvimento esboçados ao longo do tempo, o que nos permitirá melhor apreciar os contextos em que se tem negociado a adoção de abordagens de gênero. Seguese, então, uma discussão sobre as principais críticas feministas a esses modelos $e$ as negociações para a introdução, primeiro da perspectiva Mulheres em Desenvolvimento (MED) ${ }^{5}$, defendida na I $\mathrm{CMM} e$ e, posteriormente, a adoção de uma abordagem de Gênero e Desenvolvimento (GED), ${ }^{6}$ oficializada na Plataforma de Ação de Beijing (1995) e, desde então, repetidamente questionada pelos setores conservadores. Procuro destacar a atuação dos feminismos brasileiros nas conferências mundiais e negociações em questão, finalizando com uma reflexão sobre os possíveis impactos da mudança de governo $e$ ascendência dos fundamentalismos religiosos na atuação brasileira nas referidas conferências $e$ reuniões da ONU.

\section{Mulheres em Desenvolvimento (MED)}

Discursos e práticas de desenvolvimento têm suas origens nas políticas colonialistas e nos próprios movimentos de independência das antigas colônias, mas só passaram a ganhar maior atenção a partir do final da Segunda Guerra Mundial (Rai, 2011; Kabeer, 1994). A constatação do poder destrutivo dessa guerra e da consequente necessidade de reconstrução, tanto das economias e cidades atingidas, quanto das relações entre diferentes povos e países frente aos novos realinhamentos, deu margem a novas estratégias. O Plano Marshall, proposto e levado adiante pelos Estados Unidos, objetivou a reconstrução dos países

\footnotetext{
${ }^{5}$ Em inglês, Women in Development (WID).

${ }^{6}$ Em inglês, Gender and Development (GAD).
} 
mais atingidos, criando-se, em 1945, o Banco Mundial e o Fundo Monetário Internacional para apoiar ações dessa ordem. Em outubro do mesmo ano, foi criada a ONU em substituição à antiga Liga das Nações, com o objetivo de promover a cooperação internacional e a paz e segurança mundiais. Foi nesse contexto de pós-guerra que o Presidente Harry S. Truman se pronunciou sobre a existência, de um lado, dos países do Ocidente desenvolvido e, do outro, daqueles ainda em desenvolvimento, ou subdesenvolvidos, afirmando cumprir aos primeiros cooperar no desenvolvimento dos demais (Truman, 1999).

Já se verificava então um realinhamento político em torno de modelos distintos de desenvolvimento: os países desenvolvidos do Ocidente - o Primeiro Mundo - seguindo uma política neoliberal, própria às economias de mercado, ao passo que aqueles alinhados ao que viria a ser o Bloco Soviético - o Segundo Mundo - defendiam desenvolvimento dentro de uma perspectiva marxista-stalinista. $\mathrm{O}$ Terceiro Mundo era representado pelos países ditos atrasados ou subdesenvolvidos, ou ainda em desenvolvimento, abarcando as antigas colônias de países europeus (Rai, 2011).

Por certo, diferenças consideráveis - até mesmo irreconciliáveis - se interpunham entre as abordagens dos ditos Primeiro e Segundo Mundos. Todavia, havia semelhanças importantes, dentre elas a visão linear do processo de desenvolvimento com estágios definidos, ao lado da noção de que esse processo seria deslanchado com a intervenção de recursos, técnicas e conhecimentos específicos, centrados nos aspectos econômicos (Rai, 2011). Ademais, as duas abordagens mostravamse cegas - ou, no máximo, lançando um olhar assistencialista para as questões de gênero.

Na perspectiva socialista, acreditava-se que a incorporação das mulheres na força de trabalho propiciaria a sua emancipação, enquanto na perspectiva liberal, supunha-se que a modernização beneficiaria a todos, homens e mulheres, de maneira igual, os efeitos gotejando sociedade adentro. Nessa perspectiva, entendiase desenvolvimento e modernização como um mesmo processo, 
posto em marcha pela modernização dos países subdesenvolvidos nos moldes ocidentais, ou seja, na medida em que fossem adotando as tecnologias, instituições e valores ocidentais (Connelly et alli, 2000). Era, pois, necessário formular estratégias que, supostamente, criassem condições para que as economias ditas pobres, tradicionais, pudessem deslanchar e fazer a transição para a modernidade com maior rapidez.

Nos anos 1960, crises de ordem econômica, política, social e mesmo de valores varreram o mundo ocidental, abrindo espaço para críticas aos modelos de desenvolvimento. Produto desses conturbados anos, a retomada dos movimentos feministas contribuiu para a construção de um novo olhar para as questões relativas a gênero nos processos e discursos sobre desenvolvimento. Mundo afora, as mulheres passaram a demandar mais oportunidades educacionais e de emprego, maior paridade na participação política e social e acesso a serviços de saúde $e$ bem estar social, trazendo para o contexto do desenvolvimento o debate sobre justiça social e equidade de gênero (Razavi; Miller, 1995). Esse debate foi alimentado também pelo crescimento de estudos sobre mulheres em diferentes partes do mundo, retratando suas condições de vida e a situação de desigualdade a que eram submetidas.

Em Women's Role in Economic Development, a economista dinamarquesa Ester Boserup (1970) analisou o impacto de projetos de desenvolvimento na condição de mulheres do Terceiro Mundo, argumentando que a desconsideração das importantes atividades econômicas femininas trouxe consequências funestas. Além de impedir que as mulheres usufruíssem das novas oportunidades econômicas, destruiu seus meios de trabalho tradicionais e, assim, sua autonomia econômica.

Boserup ressaltou, ainda, que o suposto e propagado trickle down effect não chegava necessariamente às mulheres e que aliená-las dos programas de desenvolvimento teria impactos negativos para a sociedade como um todo. Em contraste às políticas que tomavam as mulheres como beneficiárias passivas em programas voltados para questóes de saúde e bem estar, 
Boserup representou-as como cidadãs produtivas, que deveriam ser pensadas como agentes no processo de desenvolvimento.

Em Washington, D.C., feministas ligadas a agências do governo americano passaram a pressionar por considerações sobre mulheres em políticas de desenvolvimento, negociando, por fim, a aprovação da Emenda Percy pelo Congresso Americano, que estipulou a exigência de "[...] estudos de impacto social, sensíveis a gênero, em todos os projetos de desenvolvimento, com a perspectiva de integrar as mulheres nas economias nacionais de seus países" (Connelly et alli, 2000:56). Uma intensa troca de ideias se estabeleceu entre esses grupos e mulheres trabalhando em órgãos internacionais, bem como com acadêmicas engajadas em estudos sobre o impacto de processos de desenvolvimento nas condições de vida e trabalho das mulheres (Young, 1993). Em tempo, a perspectiva Mulheres em Desenvolvimento (MED) foi incorporada pelas agências financiadoras internacionais de desenvolvimento do Canadá, Holanda, Noruega e outros países nórdicos, algumas chegando a criar setores especiais, com treinamento específico para suas equipes na formulação de políticas sensíveis a gênero $e$ na implementação de programas $e$ projetos para mulheres (Connelly et alli, 2000).

Tais políticas se baseavam nas teorias da modernização, procurando meios para incorporar as mulheres no desenvolvimento, $\mathrm{o}$ que supostamente demandaria $\mathrm{O}$ levantamento de estatísticas desagregadas por sexo, além de mais estudos sobre atividades femininas no chamado Terceiro Mundo. Essa postura se alinhava ao que se convencionou identificar como Feminismo Liberal, baseando-se na noção de que ideias estereotipadas sobre papéis sexuais interiorizadas por processos de socialização respondiam pela discriminação sexual contra mulheres. Pressupunha, assim, que mudanças viriam com o desmonte desses estereótipos e com maior acesso de mulheres $e$ meninas a educação e capacitação adequadas, bem como por acesso a crédito, mercado de trabalho e a título de propriedade, tudo isso apoiado em educação e legislação antidiscriminatórias (Connelly et alli, 2000). 
Consoante com esses pressupostos, as políticas MED se voltavam para a integração das mulheres nos programas de desenvolvimento desde sua participação em ações de planejamento. Supunham que enquanto isso não fosse prática comum, as políticas de desenvolvimento continuariam a deteriorar a situação das mulheres nos países subdesenvolvidos ou ainda em desenvolvimento, ao passo que políticas inclusivas teriam um efeito positivo no desenvolvimento econômico como um todo, sendo, portanto, mais eficientes e eficazes (Connelly et alli, 2000).

Esses argumentos ganharam espaço na $\mathrm{ONU}$, com destaque para a CSW, que conseguiu aprovar a designação de 1975 como Ano Internacional da Mulher, promovendo a realização da I Conferência Mundial das Mulheres (I CMM) na Cidade do México, de 19 de junho a 2 de julho de 1975. Participaram da I CMM 133 delegações de países membros da ONU, sendo que 113 delas foram encabeçadas por mulheres, tendo o componente feminino representado em $73 \%$ do total de 2000 delegados. O fórum paralelo - Tribuna do Ano Internacional da Mulher - teve a participação de 114 organizações, com um total de 6.000 representantes, na maioria mulheres (Moraes, 1985).

De interesse para os feminismos brasileiros foi a presença de Bertha Lutz como convidada especial da delegação brasileira, o que trouxe o reconhecimento da ONU: o embaixador brasileiro, Lauro Escorel, foi convidado a presidir a conferência. Ao destacar a presença de Bertha Lutz, ele lembrou sua importante contribuição na elaboração da Carta da ONU de 1945, no sentido de assegurar o compromisso com a igualdade entre os sexos no desenho da nova organização.

No evento, foi lançada a Década da Mulher $e$ Desenvolvimento, com uma agenda específica contida no Plano de Ação aprovado na conferência, tendo como objetivo maior "integrar as mulheres no processo de desenvolvimento" (Connelly et alli, 2000; Moser, 1993; Tinker; Bramsen, 1976). Paralelamente, discutiu-se a elaboração da Convenção para a Eliminação da Discriminação Contra Mulheres - CEDAW, aprovada em 1979, e 
desde então documento que tem legitimado a articulação das demandas feministas em prol da justiça de gênero.

Para avaliar o progresso alcançado $e$ os problemas encontrados na implementação do Plano de Ação, foi realizada em Copenhague (Dinamarca), em julho de 1980, a II CMM. Participaram 145 representações de países-membros na conferência oficial e 135 ONGs no fórum paralelo. A avaliação realizada mostrou que o objetivo traçado para essa década - a plena participação das mulheres na vida social, econômica $e$ política dos países-membros - estava longe de ser alcançado. No mundo todo, permanecia um grande descompasso entre a igualdade legalmente reconhecida $e$ a realidade de aplicação desses direitos.

Face ao que fora aprovado no Plano de Ação de 1975 e o que se constatou na Conferência de Copenhague, foi ali aprovada a realização de uma terceira conferência, a ser realizada em Nairóbi, no Quênia em 1985. O evento teve lugar de 15 a 26 de julho, reunindo representantes de 157 delegações e de 163 ONGs, tendo o total de participantes chegado a cerca de 15.000, a maioria esmagadora de mulheres.

Em preparação para essa conferência, o Conselho Estadual da Condição Feminina de São Paulo (CECF-SP), recém-criado, apoiou pesquisas sobre a condição das mulheres no país, publicando uma série de cartilhas elaboradas por pesquisadoras feministas (Moraes, 1985). Ademais, a delegação brasileira incluiu a participação de feministas de renome, não havendo, porém, uma incidência mais direta de ativismo feminista na condução da participação do Brasil. Todavia, no Fórum de ONGs, ativistas nos movimentos feministas e de mulheres de países do Sul, do Brasil inclusive, se pronunciaram com eloquência, levantando críticas a abordagem MED. Em especial, trouxeram para o debate a necessidade de se pensar desenvolvimento a partir da perspectiva das mulheres do Sul, a exemplo das propostas contidas no manifesto do DAWN-MUDAR ali discutidas (Sen; Grown, 1987).

Não se há de negar que os esforços em torno da perspectiva MED tiveram um impacto positivo. Além de incentivarem a 
realização de estudos e pesquisas sobre mulheres em muitos países, com a produção de estatísticas desagregadas que têm desde então contribuído para a formulação de políticas de combate às desigualdades de gênero, legitimaram o ativismo dos movimentos feministas na luta pelos direitos das mulheres.

No Brasil, em especial, a realização das conferências mundiais da $\mathrm{ONU}$, junto à promulgação da CEDAW, possibilitou aqui, em meio à censura e à repressão impostas pela ditadura militar, a abertura de espaços para estudos e debates sobre a condição feminina na sociedade brasileira, incluindo-se aí a criação de uma Comissão Parlamentar de Inquérito (CPI) sobre tal questão, quando propostas dessa ordem eram vistas como subversivas. Criou também as condições para o movimento feminista sair dos porões e ganhar as ruas, com o reconhecimento de demandas concernentes aos direitos das mulheres $e$ repercussão positiva na Constituinte de 1988, traduzindo demandas em direitos constitucionais (Pinto, 2003).

Mas há de se reconhecer as limitações dessa abordagem, a começar por suas reconhecidas bases na Teoria da Modernização, pressupondo a superioridade $e$ a relevância de instituições $e$ valores ocidentais para o avanço socioeconômico, incluindo-se aí o avanço das conquistas femininas (Kandyotti, 1988). Ademais, a abordagem MED, como outras com base nos feminismos liberais, não considerava as estruturas de poder patriarcais subjacentes às desigualdades entre homens e mulheres, tampouco as estruturas de dominação de classe, raça, etnicidade e outros determinantes das desigualdades entre mulheres (Razavi; Miller, 1995). Veremos a seguir como a perspectiva de Gênero e Desenvolvimento (GED) foi se construindo, vindo a substituir oficialmente a MED na IV CMM realizada em Beijing, China, em 1995.

\section{Gênero e Desenvolvimento (GED)}

Não cabe aqui retraçar os caminhos percorridos na construção do conceito de gênero na teoria feminista. Ressalte-se, porém, que em meados dos anos 1970, à época da I CMM, 
feministas já se voltavam para uma conceituação de gênero como construtor social das supostas diferenças entre os sexos, trazendo reflexões dessa ordem também para os discursos e políticas de desenvolvimento. Contudo, é certo que, atrás do termo gênero, escondiam-se - $e$ ainda se escondem - diferentes significados ou conceitos de gênero $e$, portanto, também diferentes abordagens no tocante a gênero e desenvolvimento (Sardenberg, 2014).

Trabalhando em colaboração com o Women in Development Office da USAID, pesquisadores do Harvard Institute of International Development desenvolveram um quadro de análise de papéis de gênero, usado, sobretudo, para projetos na área rural. Baseada nas teorias de papéis sexuais, alinhadas aos pressupostos dos feminismos liberais, essa abordagem se propunha a realizar um diagnóstico da divisão doméstica do trabalho e do acesso e controle sobre recursos em termos de gênero, incluindo tanto a esfera da produção quanto reprodução, tendo por objetivo maior subsidiar intervenções de sorte a incrementar a produtividade (Razavi; Miller, 1995).

Já a perspectiva de Gênero e Eficiência, também denominada Gênero e Ajustes e baseada igualmente na abordagem dos feminismos liberais, voltou-se para o nível das políticas, procurando elevar a discussão para questões macroeconômicas. Incorporou aí o discurso economista neoclássico para melhor demonstrar a planejadores que ignorar os vieses de gênero nas políticas sempre traz altos custos, não apenas sociais, mas também econômicos (Razavi; Miller, 1995). Ainda que defendendo uma perspectiva de gênero, tais abordagens têm sido alvo de críticas por parte de economistas feministas, por manterem uma aliança com os princípios neoliberais (Benería, 2003; Jain; Elson, 2011).

Ao lado dessas e outras reedições da perspectiva MED, agora utilizando o termo gênero, registraram-se, porém, avanços relevantes nas construções teóricas feministas em torno de Gênero e Desenvolvimento (GED). Já em fins dos anos 1970, surgia um grupo de acadêmicas feministas, de inclinação declaradamente socialista, no Institute of Development Studies (IDS), Inglaterra, um 
dos principais institutos de estudos $e$ formação sobre desenvolvimento em nível mundial, para discutir a questão da subordinação das mulheres (Cornwall, 2007). Esse grupo ficou conhecido como SOW - Subordination of Women, funcionando como uma oficina (workshop) para se teorizar sobre a subordinação das mulheres no desenvolvimento, tendo por base alguns pressupostos dos quais hoje muitas de nós compartilhamos.

O primeiro é que estudos sobre mulheres e desenvolvimento não deveriam partir da ideia de que "as mulheres são o problema", como proposto na abordagem MED, mas centrar o foco de análise tanto em homens quanto mulheres $e$, especificamente, nas relações entre eles (Whitehead, 1979:10). Segundo, deveriam tratar essas relações como relações de poder, socialmente constituídas, e não como derivadas da biologia. Daí porque se faria necessário utilizar o conceito de relações de gênero para distinguir as relações sociais entre homens e mulheres daquelas características que podem ser derivadas das suas diferenças anatômicas, biológicas.

O terceiro pressuposto no qual se baseou o grupo da SOW teve menos ressonância, mas talvez seja o mais importante. Parte da ideia de que as relações sociais entre homens e mulheres "[...] não são necessariamente, nem obviamente, harmoniosas ou não conflituosas". Ao contrário, essas relações podem ser tanto de cooperação quanto de oposição e conflito, ou seja, não são necessariamente complementares como anteriormente assumido. São historicamente construídas e, portanto, a forma que tomam em contextos específicos pode variar amplamente, a depender das circunstâncias (Whitehead, 1979:11). Isso implica na rejeição de políticas ditas de "tamanho único" (one size fits al), cabendo ao invés uma análise de gênero com base em investigações empíricas para melhor se conhecer esses contextos.

Para o grupo do SOW, o objetivo maior das reflexões feministas deveria ser a formulação de

[...] instrumentos analíticos e conceituais mais adequados ao desenvolvimento de uma teoria das relações sociais que 
desse conta, não apenas das ditas relações econômicas de uma sociedade, mas também do que se denominou de relações da vida cotidiana (Young et alli, 1980:viii).

Essa abordagem passou a ser reconhecida como a Perspectiva das Relações de Gênero, ou, mais amplamente, das "relações sociais" nos estudos e práticas sobre gênero e desenvolvimento, tendo grande aceitação na Europa, principalmente em centros de formação para o desenvolvimento (Cornwall, 2007).

Em 1995, pouco antes da IV CMM, novamente um grupo de feministas trabalhando na área de gênero e desenvolvimento se reuniu na Universidade de East Anglia para interrogar noções e práticas de desenvolvimento sob a perspectiva da análise das relações sociais de gênero, reafirmando os pressupostos do SOW. De fato, ali se elaborou uma crítica feminista ao desenvolvimento, voltada para questões amplas, já de longa data, "surgidas de discursos específicos com raízes no feminismo socialista dos anos 1970" (Pearson; Jackson, 1998:1).

Um desdobramento dessas abordagens que trabalham com a noção de poder se volta para a necessidade de pensar o "empoderamento" de mulheres trazendo, dessa forma, uma importante mudança de terreno - de considerações técnicas para a arena política (Razavi; Miller, 1995:31; Kabeer, 1994). Embora apresentando também versões neoliberais de empoderamento (Sardenberg, 2009), de modo geral, essa perspectiva defende a noção de que uma sociedade civil mais forte demanda governos mais representativos e responsáveis, promovendo políticas de desenvolvimento mais equitativas. Promove, assim, uma perspectiva de desenvolvimento "de baixo para cima", incentivando ações coletivas e a intervenção de ONGs feministas na conscientização e na organização de mulheres para essas ações (Razavi; Miller, 1995).

Como se verá a seguir, essa perspectiva acompanha, não apenas mudanças teórico-epistemológicas importantes no pensamento feminista, mas, sobretudo, desdobramentos das organizações e articulações de mulheres em nível global, que 
ganharam maior expressão nos anos 1990, tida como a "década das conferências". Ao lado das diferentes abordagens de gênero aqui destacadas, também a questão do empoderamento de mulheres se fez presente na elaboração da Plataforma de Ação de Beijing, quando gênero foi oficialmente adotado pela ONU.

Antes de nos voltarmos para essas conferências, vale ainda ressaltar que, mais recentemente, o debate sobre gênero em desenvolvimento tem refletido também a influência de outros importantes deslocamentos nas teorias feministas, a exemplo da crítica feminista pós-moderna (Marchand; Pappart, 1995), do debate sobre gênero e interseccionalidades (Crenshaw, 1995; Harcourt, 2016) e, nos últimos anos, sobre a colonialidade de gênero (Lugones, 2008; Mendoza, 2016; Rai, 2008). Esta última, em particular, levantada por teóricas e ativistas do chamado Terceiro Mundo, reflete também os desdobramentos dos feminismos transnacionais, discutidos a seguir.

\section{Investidas feministas na década das conferências}

Ao longo dos anos 1980, entrando nos anos 1990, mudanças importantes se verificaram no tocante aos movimentos feministas em nível mundial, com destaque para o surgimento dos feminismos transnacionais. Diferente dos feminismos internacionais, que "existem pelo menos desde os primórdios do século vinte", mas articulados em torno de questões nacionais, os feminismos transnacionais se constituem de movimentos $e$ organizações que buscam um "cruzar consciente de fronteiras nacionais e a superação de orientações nacionalistas" (Moghadam, 2005:82).

Segundo Valentine Moghadam (2005), a retomada do feminismo nos anos 1960 e 1970, a chamada "segunda onda do feminismo", respondeu, inicialmente, a contradições nacionais internas, levando os movimentos a se orientarem sobremaneira para questões nacionais. Essa tendência revelou-se de forma contundente na I CMM na Cidade do México, em 1975. Além das diferenças políticas e ideológicas expressas pelos participantes, 
grande parte das delegações ainda era constituída por homens, acirrando-se assim as discussões em torno da formulação do Plano de Ação. Situação semelhante repetiu-se em Copenhague, em 1980.

A maior participação de feministas e de ativistas nos movimentos de mulheres na preparação da III CMM, em Nairóbi, 1985, aliviou muitas das divergências regionais e ideológicas, ao mesmo tempo que promoveu o surgimento de organizações feministas e de mulheres transnacionais, a exemplo da DAWNMUDAR (Sen; Grown, 1987). Isso resultou, em grande medida, da própria globalização das economias, o que deu margem à uma "[...] nova conscientização, influenciou a formação de novas organizações de mulheres, $e$ inspirou uma nova forma de organização e mobilização de mulheres" (Moghadam, 2004:88). Essa nova forma rejeita nacionalismos em favor da "solidariedade através de fronteiras", o que Moghadam vê como característica dos feminismos transnacionais.

Por certo, os órgãos e agências da ONU tiveram um importante papel nesse processo, facilitando a interação $e$ a cooperação entre diferentes organizações feministas. O próprio espaço das conferências, principalmente dos fóruns paralelos, promoveu as trocas entre feministas de diferentes países, bem como legitimou as lutas das mulheres nos contextos nacionais, com destaque para campanhas em prol dos direitos sexuais $e$ direitos reprodutivos das mulheres (Antrobus, 2004; Jain, 2005).

Ao mesmo tempo, como destaca Virginia Vargas (2010:319), a transição dos anos 1980 para 1990 foi "[...] acompanhada de novos cenários políticos, ideológicos, econômicos e culturais que influenciaram o feminismo $e$ outros movimentos sociais de maneira geral". Abriram-se novas arenas com o avanço da democracia, tornando possível e legitimando o discurso sobre direitos, ainda que, nem sempre, Estado e sociedade civil concordassem na interpretação desse discurso, dando margem a "guerras de interpretação". Nesse tocante, os feminismos buscaram 
[...] não apenas acesso à igualdade, mas também reconhecimento da diversidade e diferença, acesso não apenas aos direitos existentes, mas também ao processo de descoberta e expansão permanente de direitos, criando novos significados sociais (Vargas, 2010:319).

Note-se que no período em questão, também na sociedade brasileira se operaram mudanças significativas, marcadas pela redemocratização do país. Os movimentos feministas tiveram um papel relevante nesse processo, assegurando direitos fundamentais para as mulheres na Constituição de 1988. Acordos estabelecidos com as forças de oposição nas primeiras eleições para governadores, depois de quase vinte anos, incidiram também na criação dos conselhos dos direitos das mulheres, bem como das delegacias especializadas de atenção às mulheres em situação de violência e na formulação e implementação do Programa de Atenção Integral à Saúde da Mulher (PAISM), que implicou no atendimento pela rede de saúde pública dos casos de abortamento permitidos por lei (Sardenberg; Costa, 2010).

Mas é bom observar: o feminismo no país também se modificou bastante desde então. Deixou de ser um movimento basicamente de mulheres brancas, de classe média, para incorporar brasileiras de diferentes setores da sociedade, diversificando-se a ponto de ser necessário falarmos hoje de "feminismos" no plural (Alvarez, 2014; Sardenberg; Costa, 2010; 2017). Verificou-se, também, a crescente profissionalização dos feminismos com o surgimento das ONGs, além da sua institucionalização com os estudos feministas nas universidades (Alvarez, 2000). Avanços foram registrados, ainda, nos espaços globais, construídos pelas conferências das Nações Unidas, propiciando a expansão das redes feministas pelo país e a transnacionalização dos feminismos brasileiros (Alvarez, 2014; Pitanguy, 2002).

Esse processo se fez sentir, principalmente, a partir da realização da Cimeira Mundial das Nações Unidas sobre Ambiente e Desenvolvimento (ECO 92) com o Fórum das ONGs, realizados 
paralelamente no Rio de Janeiro, em 1992. As ações feministas se deram, sobretudo, no espaço do Planeta Fêmea, liderado por feministas brasileiras. Sob uma grande tenda armada no fórum paralelo, foram realizadas, diariamente, várias oficinas, reuniões, debates e discussões em torno de uma grande variedade de temas relativos a meio ambiente e desenvolvimento, incluindo-se a formulação de uma agenda das mulheres para um planeta mais saudável - a Women's Action Agenda for a Healthy Planet (WAA21).

Feministas brasileiras também tiveram uma importante atuação na Conferência Mundial sobre os Direitos Humanos, realizada em Viena, Áustria, em junho de 1993. Elas participaram tanto da delegação brasileira, quanto do Fórum de ONGs, onde, tal como no Rio 92, oficinas, debates, conferências, apresentações artísticas, exposição de fotos e atividades dessa ordem atraíram a atenção de participantes para as questões relativas à equidade de gênero.

Em preparação para Viena, as ONGs feministas organizaram pré-conferências, mostrando-se bem articuladas e com força em números, de sorte a garantir várias referências aos direitos das mulheres - $e$ até mesmo um artigo específico reconhecendo os direitos das mulheres como direitos humanos - na declaração final da conferência. Sobre a participação brasileira nesse processo, assim relatou Schuma Schumaher ${ }^{7}$, da ONG Redeh:
A diplomacia brasileira teve sempre posições muito avançadas, se a gente comparar com os nossos países vizinhos, países irmãos, os países da América Latina, do Caribe. Era impressionante, não só para nós, como as nossas companheiras feministas de outros países ficavam na dependência do Brasil. O Brasil confiava na sociedade civil integrar a sua delegação oficial. Os encaminhamentos, as propostas eram todas feitas de comum acordo com a

\footnotetext{
7 Entrevista realizada no Rio de Janeiro em 22/06/2011. Utilizo os nomes verdadeiros das pessoas entrevistadas, vez que todas assinaram termo de concordância nesse sentido.
} 
delegação oficial (...) da sociedade civil incluída na delegação oficial.

Estratégias semelhantes foram utilizadas para a Conferência Internacional sobre População e Desenvolvimento, realizada no Cairo, Egito, em 1994 (Schumaher, 1995). Sabe-se que, no contexto das conferências, sempre houve dificuldade em se construir o consenso quanto ao reconhecimento dos direitos reprodutivos $e$ dos direitos sexuais das mulheres, sendo essa dificuldade ainda maior nos caso destes últimos. Por isso mesmo, ONGs feministas reuniram cerca de 300 ativistas de diferentes países para construírem um consenso sobre esses direitos e a importância de diferenciá-los, havendo também, no Brasil, uma intensa articulação de feministas nesse sentido. Segundo observou Leila Barsted $^{8}$, do CEPIA:

Eu não fui a Cairo, mas participei de todas as reuniões préCairo, as nacionais. E a atuação das feministas aqui foi assim fundamental. Tanto que levar uma reunião pré-Cairo para o Congresso Nacional, por exemplo, foi uma coisa importantíssima.

De fato, uma posição progressista marcou a atuação do Brasil nas negociações mais delicadas de propostas incluídas no Programa de Ação de Cairo, particularmente as contidas nos parágrafos 7.2 e 7.3 que lidavam com o reconhecimento dos direitos reprodutivos (Corrêa, 2004). Isso levou ao rompimento do Brasil com o G-77 e com o Vaticano e seus aliados, principalmente no tocante à legalização do aborto. Refletindo sobre sua participação nessa conferência, Gilda $\mathrm{Cabral}^{9}$, do CFêmea, assim se expressou:

Eu vivi esse processo, a sensação de como é importante você se sentir parte da história. Estar lá faz, fez diferença. $\mathrm{O}$

8 Entrevista realizada no Rio de Janeiro em 27/06/2011.

9 Entrevista realizada em Brasília em 01/06/2011. 
que mais achei interessante na conferência mesmo lá no Cairo foi a integração da América Latina, porque nós tínhamos regionalmente na América Latina e Caribe uma articulação das mulheres na área de saúde. Na conferência, o aborto para a gente era uma coisa muito importante, era uma batalha. [...] A gente levava propostas muito consensuais entre a gente. Mesmo para os países onde os governos tinham posição muito diferente como Guatemala, Argentina e não sei o que, na coisa do Aborto, o movimento social, as ONG's e tal, no paralelo, na conferência paralela, a gente estava sempre fechado pela legalização.

Todas as conferências mundiais da década contribuíram para o fortalecimento dos feminismos brasileiros nos espaços globais, no entanto, foi a IV CMM, realizada em Beijing de 04 a 15 de setembro de 1995, que teve um maior impacto, tanto em casa quanto no exterior. Ela também propiciou o estreitamento do diálogo dos movimentos com o Estado, interrompido pelo desmantelamento do CNDM durante o governo do Presidente Collor.

Já em dezembro de 1993, buscando elaborar um relatório para a ONU, o Itamarati criou uma comissão composta pelos membros do CNDM e do Fórum Nacional de Presidentes de Conselhos Estaduais. Engajou também a assessoria de ativistas feministas para a organização de cinco seminários nacionais, realizados em torno de temas distintos em diferentes regiões do país, convocando a participação de militantes de diferentes movimentos sociais. Embora nem sempre caminhando sem conflitos, esse processo transcorreu em um clima cordial de diálogo e colaboração entre governo federal e ativistas, que se manteve até recentemente (Libardoni, 1996; Saffioti, 1995).

Contudo, iniciativas para uma articulação nacional feminista autônoma vinham sendo tomadas desde as reuniões preparatórias para Cairo. Em janeiro de 1994, foi realizado um encontro no Rio de Janeiro com cerca de 100 mulheres, representando 16 estados, para se discutir a participação feminista em Beijing. Foi então 
criada a Articulação de Mulheres Brasileiras Rumo a Beijing, depois oficializada como Articulação de Mulheres Brasileiras (AMB), mobilizando mulheres em todo o país.

Com o slogan "Beijing é Aqui", a AMB promoveu a articulação de mulheres em fóruns $e$ articulações estaduais, realizando cerca de 90 eventos com a participação de 800 organizações. O principal evento aconteceu no Rio de Janeiro em junho de 1995, reunindo mais de 700 ativistas representando quase todos os estados, quando foi aprovada a Declaração Política delineando a principal demanda dos grupos participantes: o compromisso das delegações oficiais de que Beijing trouxesse, se não verdadeiros avanços, pelo menos nenhum retrocesso em relação às conquistas das conferências anteriores (Haddad, 2007; Soares, 1995).

Essa questão foi trabalhada no Fórum Regional de ONGs preparatório para a IV CMM, realizado em Mar del Plata, Argentina, de 20 a 24 de setembro de 1994, reunindo mais de 1.200 participantes de 41 países da região. Foram aí votados, tanto na reunião oficial das representações governamentais, quanto no Fórum de ONGs, os documentos regionais da América Latina e o Caribe. O Brasil compareceu com mais de 100 representantes, formulando uma posição progressista em defesa da perspectiva de gênero e dos direitos das mulheres como direitos humanos, direitos sexuais e direitos reprodutivos e combate à violência racial e étnica. A presença de ativistas feministas na delegação oficial foi fundamental para a defesa dessas propostas pelo nosso corpo diplomático, garantindo sua inclusão no documento regional.

Além disso, essa pré-conferência se constituiu como um espaço importante de articulação das feministas negras latinoamericanas, a exemplo do painel organizado pelo Geledés Instituto da Mulher Negra: "Mulhers Negras Latino-Americanas e Caribenhas - Balanço e Perspectivas para o III Milênio", que procurou dar visibilidade à luta das mulheres negras (Ribeiro, 1995).

Por certo, a principal pré-conferência - e o primeiro grande teste para a pauta mais progressista - teve lugar na $39^{\mathrm{a}}$ Reunião 
da CSW, realizada em N. Iorque em março de 1995, quando o esboço da Plataforma de Ação foi finalizado para aprovação em Beijing. Houve grande controvérsia na compilação do documento final, deixando-o marcado por colchetes, indicando que em boa parte das questões - principalmente aquelas relativas aos direitos sexuais e reprodutivos - não havia acordo (Abramovay, 1995). Não havia acordo também em relação ao uso da perspectiva de gênero, questão fundamental para as feministas.

O Vaticano liderou as manifestações contra o uso de gênero, como parte de sua campanha contra o feminismo. Esse ataque era motivado não apenas pelo crescimento do feminismo em escala global, como também para tornar a Igreja um baluarte da luta contra o "capitalismo selvagem", colocando as lutas feministas no mesmo plano das políticas controlistas de organizações internacionais (Franco, 2003:30). O Vaticano repetia, assim, sua posição contra os direitos sexuais e reprodutivos expressa tanto na ECO 92 quanto em Cairo, juntando esforços com os países islâmicos para bloquear qualquer avanço nessa direção. Quando não conseguia retirar esses artigos dos documentos, demandava que fossem colocados entre colchetes, tática essa da qual se serviu sem parcimônia nas discussões em torno da Plataforma de Ação a ser apresentada em Beijing (Franco, 2003:34). Pouco antes da abertura da Conferência, já em Beijing, o porta-voz do Vaticano se referiu ao rascunho dessa Plataforma como um documento "ideologicamente desequilibrado", que impunha um modelo ocidental de feminilidade a outras mulheres do mundo, além de colocar um ênfase demasiado em "gênero" e "sexualidade", pouco considerando a maternidade (Franco, 2003:35). Uma postura que tem sustentado críticas também aos estudos de gênero na contemporaneidade (Castro, 2018).

Para assegurar um esforço mais harmônico na Regional da America Latina e do Caribe, região na qual a Igreja tinha muita força, realizou-se um encontro em Santiago, no Chile, às vésperas da IV Conferência, reunindo representantes oficiais dos paísesmembros para se comparar o documento regional, tirado antes em Mar del Plata, com o que resultou da reunião da CSW em N. 
Iorque. Tentou-se, então, apagar os "colchetes", ao menos no nível regional, com a concordância de que cada país estaria livre para seguir defendendo, em Beijing, as questões sem consenso na região.

Já no Fórum de ONGs da América Latina e do Caribe, a articulação foi bem melhor costurada. Além das conferências preparatórias regionais, as ativistas feministas da região vinham se articulando periodicamente nos famosos Encuentros Feministas Latinoamericanos y del Caribe (Sternbach et alii, 1992), realizados então a cada três anos, mobilizando articulações e redes regionais em defesa dos direitos sexuais e reprodutivos e enfrentamento da violência contra mulheres. Isso contribuiu para que se construísse uma posição bem melhor orquestrada do que a da representação oficial. Assim, em Beijing, mesmo contando com um grupo relativamente pequeno (um total de cerca de 2000 mulheres, 300 delas do Brasil), esse grupo da América Latina e do Caribe levou vantagem por sua posição bem articulada. Ademais, na Tenda da Diversidade, organizada pelas participantes latino-americanas $e$ caribenhas, foram promovidas várias atividades diárias para a troca de informações e experiências e construção de intervenções mais harmônicas (Haddad, 2007).

Em Beijing, feministas brasileiras participaram ativamente tanto no Fórum de ONGs, quanto na delegação oficial. Suas vozes se faziam ouvir no fórum, trazendo subsídios para os debates oficiais, sendo às vezes necessário correr de um evento para o outro - acontecendo em cidades diferentes, o Fórum de ONGs em Houairou e o oficial em Beijing, com mais de 30 minutos de viagem entre um e outro - para defender uma questão crucial. À bem da verdade, a delegação oficial se reunia diariamente com representantes das ONGs, quando se discutiam as questões prementes, negociava-se a posição oficial do Brasil e estratégias para defendê-la. Conforme revelou Schuma Schumaher ${ }^{10}$ :

\footnotetext{
${ }^{10}$ Entrevista realizada no Rio de Janeiro em 22/06/2011.
} 
Em Beijing [...]70\% da delegação de quem atuou, de fato, politicamente nas negociações para a Plataforma da Mulher de Beijing foi a sociedade civil. Quer dizer, muitas conselheiras do CNDM da sociedade civil na delegação oficial, que tinha como liderança Ruth Cardoso. De certa forma, todo mundo sabia na América Latina, todo mundo conhecia que ela era uma mulher comprometida com o feminismo, com a causa das mulheres. Então, tivemos uma delegação muito progressista, com posições muito avançadas e que deu muitas alegrias ali para as brasileiras que estavam mais perto desse processo.

Schuma Schumaher revelou, ainda, que durante a conferência, as articulações com feministas de outros países da América Latina foram intensas, bem como as trocas entre governo e sociedade civil:

Articulamos principalmente com as latinas e o tempo inteiro. Era bem engraçado, porque teve um processo de diálogo muito intenso. Por exemplo, sabíamos que o México estava com uma posição na secretaria da mesa, então, a embaixadora do México tinha papel importante em determinado momento. As mexicanas traziam essas informações para a gente e nós levávamos para os nossos e as nossas negociadoras também da nossa comissão. Quer dizer, eu acho que essa troca de informação e de interação entre as feministas que iam monitorando e alimentado com informação a própria representação oficial contribuía muito.

Um destaque foi a visita da Dra. Ruth Cardoso, Chefe da Delegação Brasileira, à Tenda da Diversidade:

A primeira visita oficial à tenda foi da delegação brasileira com a dona Ruth Cardoso com todo aquele aparato, com segurança e tal. Aquilo criou um fuzuê, uma festança, uma algazarra, que começaram as outras latinas que tinham uma relação razoável, que tinham uma delegação oficial razoavelmente democrática, a também querer levar. Então, nós começamos a receber delegações oficiais na nossa 
tenda todos os dias. [...] eu acho que foi o Brasil que puxou essa história de que o governo faz essa deferência, sai de Beijing vai para Houairou para reconhecer a força, o poder, a articulação, a mobilização da sociedade civil.

Um depoimento semelhante foi oferecido por Lia Zanotta Machado $^{11}$, que assim se expressou:

A delegação brasileira é uma delegação que defende os direitos das mulheres. Ela está muito afinada, digamos, com os representantes das organizações não governamentais, das lideranças feministas que estão lá. [...] A delegação brasileira, o que é que ela fez? Ela abriu a possibilidade de feministas participarem da delegação.

Dentre os pontos mais polêmicos levados para discussão na IV Conferência, estava a incorporação do conceito de gênero na Plataforma de Ação de Beijing, um conceito largamente rejeitado pelo Vaticano e por países Islâmicos (Machado, 1995; Baden; Goetz, 1997), que também se opuseram à inclusão da questão dos direitos sexuais e reprodutivos, particularmente quanto à legalização do aborto como um direito das mulheres. Junto ao Brasil, o Japão, os Estados Unidos e a União Europeia lutaram pela inclusão da frase "direitos sexuais das mulheres", no entanto, as forças conservadoras lideradas pelo Vaticano se mostraram irredutíveis. $\mathrm{O}$ máximo que a frente mais progressista conseguiu avançar se deu em relação ao reconhecimento do controle sobre a sexualidade como um direito humano. Em relação aos direitos reprodutivos, a delegação brasileira foi bem sucedida na sua argumentação a favor da inclusão dos pontos aprovados em Cairo. Contudo, não conseguiu avançar no tocante à descriminalização do aborto, à exceção do consenso quanto à recomendação de que os países membros revissem sua legislação punitiva contra mulheres que praticassem abortos ditos ilegais (Haddad, 2007).

${ }^{11}$ Entrevista realizada em Brasília em 07/06/2011. 
A delegação brasileira foi ainda creditada pelo reconhecimento da relevância do trabalho das mulheres, particularmente o não remunerado, bem como pela inclusão de questões de raça e etnicidade como determinantes de discriminação contra mulheres, uma questão vista como essencial no combate contra as desigualdades sociais.

Avaliando a participação brasileira nessas importantes conferências, particularmente a de Beijing, Leila Barsted assim declarou:

Houve nessas duas conferências essa sinergia, essa sensibilidade dos nossos diplomatas dialogarem com os movimentos de mulheres no Brasil, de terem uma visão mais aberta em relação às questões das mulheres, exatamente porque tínhamos uma constituição que reconhece direitos, e, ao mesmo tempo, de serem capazes também de absorver os avanços e de tentar impedir os retrocessos, porque toda a negociação de Cairo e de Beijing foi uma negociação dura contra os setores fundamentalistas. E o Brasil sustentou isso. Então, eu acho que foi uma coisa muito positiva.

Da mesma forma, a participação nessas conferências teve um impacto importante para a articulação de feministas brasileiras com as de outros países nesses espaços transnacionais. No dizer de Schuma Schumaher: "Uma das coisas mais importantes para as brasileiras no processo de Beijing, na minha avaliação, foi ser esse o primeiro momento em que nós existimos como latinas, com uma identidade latina".

Os feminismos brasileiros também tiveram papel importante na III Conferência Mundial contra o Racismo, a Discriminação Racial, Xenofobia $e$ as Formas de Intolerâncias Correlatas, realizada em Durban, na África do Sul, em outubro de 2001. Essa conferência classificou a escravidão e o tráfico de escravos como crimes contra a humanidade, dando início, no Brasil, à discussão $e$ à implementação de políticas de ação afirmativa. Foi, portanto, 
um momento importante para os feminismos brasileiros, tal qual observou Guacira de Oliveira ${ }^{12}$, do CFEMEA:

Em 92, em Beijing e Durban a gente, Brasil, tem uma presença, em termos de movimento, estupenda, né? Aí eu acho que a gente coloca a nossa cara, o nosso jeito de fazer política, influencia muito o espaço latino-americano com isso. [...]. Em Durban se encontram feminismos parecidos com o nosso no mundo. Aí vai se encontrar o feminismo brasileiro, a maior parte do feminismo africano, uma parte do feminismo asiático e tal em agendas comuns, em construções comuns dentro da conferência. Acho que foi um espaço de maiores encontros nesse sentido.

Vale aqui observar que os debates travados em Durban legitimaram também a incorporação da perspectiva da interseccionalidade de gênero com outros elementos constitutivos das relações sociais, tais como raça e classe, nas discussões sobre gênero e desenvolvimento (Crenshaw, 1995). Ao lado das importantes conquistas obtidas nas conferências mundiais da década de 1990 no tocante à incorporação da própria perspectiva de gênero e da defesa dos direitos sexuais e dos direitos reprodutivos das mulheres, evidenciadas na Plataforma de Ação de Beijing, tal perspectiva contribuiu para abordagens mais inclusivas e, certamente, mais avançadas, nos discursos em torno de desenvolvimento quanto à gênero. Todavia, como se verá a seguir, esses avanços têm encontrado grande resistência por parte de correntes conservadoras desde então, obrigando uma atuação combativa de ativistas feministas em sua defesa, com a participação dos feminismos brasileiros.

\section{Defendendo a Plataforma de Ação}

A Declaração de Beijing e a Plataforma de Ação estão dentre os documentos internacionais mais avançados na

\footnotetext{
${ }^{12}$ Entrevista realizada em Brasília em 09/06/2011.
} 
construção da justiça de gênero. A Plataforma, em especial, promove a equidade de gênero como questão de relevância para toda a sociedade - e não apenas de interesse das mulheres afirmando-se ser da responsabilidade dos governos dos países signatários a construção dessa sociedade mais justa. Ali se estabeleceu o empoderamento das mulheres como uma de suas principais metas, definindo a transversalização do enfoque de gênero (gender mainstreaming) como estratégia fundamental para a construção da equidade de gênero e comprometendo os referidos governos a se empenharem nesse processo, nos seguintes termos:

[...] governos e outros atores devem promover uma política ativa e visível de transversalização da perspectiva de gênero em todas as políticas e programas, de sorte que, antes de decisões serem tomadas, proceda-se a uma análise dos seus efeitos sobre mulheres $e$ homens, respectivamente (United Nations, 1995:27).

Esses avanços em relação ao Plano de Ação de 1975 resultaram de muitas discussões $e$ negociações $-e$ às vezes de verdadeiras batalhas! E a cada cinco anos, desde então, outras batalhas precisam ser vencidas para se garantir que não haja retrocessos. Essa batalha foi árdua já na Sessão Especial da Assembleia Geral da ONU, melhor conhecida como "Beijing +5 " (em alusão aos cinco anos passados da IV Conferência Mundial sobre a Mulher), realizada em N. Iorque, em junho de 2000, para avaliar os avanços na implementação da Plataforma de Ação. Os embates para se garantir a manutenção da perspectiva de gênero no documento final levaram ao surgimento de um novo grupo dentro do G-77: o Some Latin American Countries (SLAC), um grupo de países da América Latina com propostas mais progressistas (Alves; Corrêa, 2003).

O Brasil foi uma das principais lideranças, mas não sem a pressão vinda de organizações feministas no país. A AMB estimulou discussões realizadas nos fóruns locais e nas articulações estaduais de mulheres, com vistas à avaliação da implementação 
das políticas públicas para mulheres no Brasil desde a IV CMM, promovendo a realização de um encontro nacional, em janeiro de 1999, para se discutir os resultados. Enquanto isso, o governo federal criava uma comissão nacional para elaborar um relatório a ser encaminhado à $\mathrm{ONU}$, contudo, desta feita sem um diálogo mais próximo com a sociedade civil. Mas as organizações feministas pressionaram o governo com duas importantes demandas: a) apresentação e discussão do relatório oficial com o movimento e; b) inclusão de representantes dos movimentos feministas e de mulheres na delegação brasileira (Sant'Anna, 2000).

Resistente no início, o Itamarati acabou respondendo favoravelmente a essas duas demandas, atuando de forma progressista na conferência regional e nos encontros preparatórios, realizados durante a $44^{\mathrm{a}}$ sessão da CSW em março de 2000, preparando assim o terreno para a Beijing +5 que aconteceria em junho do mesmo ano. Para tanto, a AMB promoveu um encontro nacional em João Pessoa, onde uma declaração política conhecida como Carta da Paraíba - foi aprovada, lembrando o governo brasileiro do seu compromisso de defender e avançar na implementação da Plataforma de Beijing.

Em sessão especial, foi aprovado o Documento de Revisão da Plataforma de Ação, uma análise dos avanços registrados desde 1995 e de como avançar ainda mais. Foi um documento promessa de que os países-membros se comprometiam a tornar realidade as medidas que foram acordadas e assim implementar de forma mais rápida as disposições da Plataforma de Beijing.

Mas o novo milênio abriu também novos espaços de interlocução para os feminismos transnacionais, a exemplo dos encontros do Fórum Social Mundial (FSM), realizados em 2001, 2002 e 2003 em Porto Alegre. As feministas brasileiras marcaram presença nesses espaços e em outros encontros do FSM, seja como membros de suas próprias organizações e grupos, ou de redes mais amplas, tais como a Marcosul e a Marcha Mundial de Mulheres (Alvarez; Libardoni, 2003).

Em todos esses espaços, os feminismos brasileiros foram reconhecidos por uma postura dita "progressista", sustentada por 
articulações que pressionam por e monitoram a implementação de políticas públicas em defesa do empoderamento de mulheres no país. Essas articulações feministas organizaram um grande encontro de feministas em Brasília antes das eleições de 2002, reunindo mais de 2000 feministas, para elaborar a Plataforma Política Feminista (PPF), apresentada aos candidatos à Presidência da República.

Fiel ao compromisso assumido em relação à plataforma, o Presidente Lula criou, em 2003, a Secretaria Especial de Políticas para Mulheres (SPM) com status de ministério, declarando 2004 como "Ano das Mulheres" no Brasil e convocando a I Conferência Nacional de Políticas para Mulheres (I CNPM), a ser realizada em Brasilia em junho daquele ano. Cerca de 2000 delegadas, eleitas em conferências municipais e estaduais realizadas por todo o país, se reuniram em Brasilia em um diálogo entre sociedade civil e Estado - do nível municipal ao federal - para a formulação do primeiro Plano Nacional de Políticas para as Mulheres (I PNPM). A II CNPM, realizada em 2007 e, a III CNPM, em 2010, ajustaram e avançaram nos planos anteriores, consolidando uma forma de "feminismo de Estado participativo", ou seja, um Feminismo de Estado que opera com "[...] mecanismos participativos, tais como, conselhos e conferências, do plano local ao global" (Sardenberg; Costa, 2010:281; 2017).

Desde então, foram essas conferências e os planos delas resultantes que orientaram, não apenas as políticas públicas para mulheres no âmbito nacional, como também a posição oficial do Brasil nos espaços globais, os da ONU em especial. A bem da verdade, na Conferência de Beijing +10 , realizada em fevereiro de 2005, como parte da $49^{\mathrm{a}}$ Reunião da CSW, ainda não se tinha o I PNPM totalmente formulado e acordado. Mas a SPM organizou um seminário de um dia em Brasília, reunindo representantes de órgãos do governo, organizações internacionais, especialistas $e$ ativistas feministas para avaliar e discutir os avanços e desafios na implementação do Plano de Ação. Seminário semelhante foi organizado pela Câmara dos Deputados, com o intuito de discutir 
os compromissos assumidos em Beijing e preparar uma comissão de deputadas que integrariam a delegação brasileira.

A Conferência de Bejing +10 foi a primeira em que uma Ministra de Políticas para Mulheres do Brasil teve participação, no caso, a Ministra Nilcéa Freire. Ela proferiu uma corajosa fala sobre a temática posta - Objetivos de Desenvolvimento do Milênio (MDGs) e Plataforma de Ação de Beijing -, enfatizando que enquanto a Plataforma de Beijing contemplava todos os Objetivos do Milênio, a recíproca não era verdadeira. Era, pois, fundamental incorporar as estratégias definidas em Beijing nos Objetivos do Milênio, já que "[...] a discriminação e violência contra mulheres são fatores que contribuem para o seu empobrecimento $e$ marginalização no mercado de trabalho" (Bastos, 2005). Tal questão foi, de fato, incorporada na Declaração de Beijing +10 , em que se enfatizou a necessidade da incorporação de uma perspectiva de gênero na Declaração dos Objetivos do Milênio (Brichta; Viotti, 2011).

Em março de 2010, foi realizada a Conferência de Beijing +15 , junto à $54^{\mathrm{a}}$ Sessão da CSW, reunindo não apenas delegações oficiais, como também mais de 8000 mulheres ligadas a organizações não governamentais para trocar experiências $e$ avaliar as "boas práticas" na implementação da Plataforma de Beijing no fórum paralelo. Contudo, a tônica dessa conferência foi marcada pela crise mundial - financeira, econômica, energética, climática, social - e pela falta de interesse pela Plataforma de Beijing em favor dos Objetivos do Milênio. Não ao acaso, as organizações feministas mundo afora consideraram a Declaração de Beijing+15 como um "mero instrumento técnico, um documento despolitizado e sem uma perspectiva crítica, resultante do pouco espaço aberto para a participação das organizações da sociedade civil" (García Prince, 2010).

Embora participando em número mais reduzido, feministas brasileiras estiveram presentes em encontros e conferências regionais e na Conferência de Beijing +15 , como parte da delegação coordenada pela Ministra Nilcéa Freire, que se pronunciou com veemência, ressaltando a necessidade de 
desconstrução do machismo e da discriminação contra as mulheres.

Após as reuniões de Beijing +15 , consultas foram realizadas entre diferentes organizações para se deliberar sobre a realização de uma nova conferência mundial em 2015. Os resultados mostraram existir um grande receio entre grupos mais progressistas de que tal conferência pudesse colocar em risco os avanços conquistados. No Brasil, organizações feministas $e$ governo, representado pela SPM, concordaram em evitar o risco maior, defendendo a realização da conferência de Beijing +20 , que teve lugar durante a $59^{\mathrm{a}}$ sessão da CSW, em N. York, em março de 2015.

Indicada pela primeira mulher Presidenta do Brasil, Dilma Rousseff, como Ministra da Secretaria de Políticas para Mulheres, a Dra. Eleonora Menicucci, feminista de longa data, presidiu à XII Conferência Regional realizada em novembro de 2013, em Santo Domingo. Argumentando em favor de uma atuação regional concertada na conferência maior, a Ministra defendeu, não apenas as recomendações da Plataforma de Ação, como também a necessidade de aprovação da inclusão dos direitos LGBT. ${ }^{13}$

Todavia, à época da conferência de Beijing +20 , ocorrida em março de 2015, já se articulava o golpe contra o Governo Dilma, com o Deputado Eduardo Cunha, Presidente da Câmara Federal, bloqueando todos os programas e medidas propostas pelo governo que acabara de iniciar seu segundo termo. Ao mesmo tempo, grupos de direita, incitados pelo PSDB, partido vencido nas eleições de 2014, comandavam protestos nas ruas pedindo o impeachment da Presidenta.

Para apoiá-la, a Ministra Eleonora Menicucci não participou da Conferência de Beijing +20 , sendo representada pela

\footnotetext{
${ }^{13}$ Aliás, o Brasil também sempre teve uma postura avançada em relação à defesa desses direitos, seja no plano regional quanto global. Foi a delegação brasileira que propôs à Comissão de Direitos Humanos da ONU a resolução sobre Direitos Humanos e Orientação Sexual, defendendo a promoção e a proteção dos direitos humanos de todas as pessoas, independente de sua orientação sexual (Friedman, 2010).
} 
subsecretária Linda Goulart que, seguindo a linha progressista da $\mathrm{SPM}$, fez um forte pronunciamento defendendo a perspectiva de gênero $e$ os direitos das mulheres como direitos humanos nesses termos:

Para o Brasil, a busca da igualdade de gênero e do empoderamento das mulheres e meninas é uma política de governo e uma política de Estado. Não pode haver dúvida de que para o Brasil os direitos das mulheres são direitos humanos (Goulart, 2015).

Mais de 11.000 pessoas participaram dessa conferência. E mais de 8.000 delas marcharam na passeata do dia 8 de março, Dia Internacional da Mulher, promovida pela ONU e prefeitura de Nova York, demonstrando seu apoio ao cumprimento dos compromissos firmados em Beijing. Cientes das ameaças que pairavam sobre a manutenção desses compromissos, bem como das tentativas de reduzir a participação da sociedade civil nos debates, ativistas feministas de América Latina e Caribe abriram o evento com uma manifestação nos portóes da ONU, usando esparadrapo na boca para simbolizar o "cala boca" imposto às ONGs (Sardenberg, 2015).

Mais uma vez, a manutenção do conceito de gênero e dos direitos das mulheres como direitos humanos, foco dos debates com representações conservadoras em Beijing, resultou na elaboração de um pré-documento com colchetes e calorosos embates noite adentro nas reuniões de Beijing +20. Desta feita, também a representação brasileira liderou as forças progressistas, não permitindo retrocessos, de sorte que o documento final reafirmou a centralidade de equidade de gênero e da necessidade de se promover o empoderamento de mulheres. Por sua marcante atuação nessas conferências defendendo a Plataforma de Beijing, a representação brasileira foi convidada a presidir, na pessoa do Embaixador Antonio Patriota, a $60^{\mathrm{a}}$ sessão da CSW, que teve lugar de 14 a 24 de março de 2016. 
De fato, o Brasil não só assumiu a presidência desse evento, como também organizou, em colaboração com a ONU-Mulheres e o Comitê Olímpico Internacional, uma sessão especial sobre a contribuição dos esportes para avançar no sentido da "equidade de gênero" e erradicação da violência contra mulheres. Pouco tempo depois, porém, antes mesmo da abertura das Olimpíadas de 2016 no Rio de Janeiro, a Presidenta Dilma, legitimamente eleita em 2014, seria deposta por um golpe de Estado, mascarado em um processo de impeachment. Na seção a seguir, trataremos do impacto desse golpe nas políticas para mulheres no Brasil e o que isso pode significar também para nossa atuação nas esferas internacionais.

\section{O Brasil do pós-golpe}

Durante o ano de 2015, os movimentos feministas e de mulheres no Brasil mostraram a sua força, levando às ruas um grande número de mulheres de diferentes segmentos em defesa dos seus direitos. Em agosto, chegaram a Brasília mais de 30.000 mulheres participantes da Quinta Marcha das Margaridas, que reuniu trabalhadoras rurais, agricultoras, mulheres indígenas $e$ quilombolas. Em novembro, mais 10.000 mulheres negras de todo o país marcharam em Brasília, para se manifestar contra o racismo $e$ a violência contra as mulheres. Ao longo do ano, o movimento Marcha das Vadias tomou conta das ruas em várias cidades do país protestando contra a violência sexual $e$, durante outubro $e$ novembro, viu-se o desabrochar da Primavera das Mulheres, com as marchas lideradas por feministas protestando contra O PL 5.069/2013, de autoria do presidente da Câmara dos Deputados Eduardo Cunha (PMDB-RJ), que criava toda sorte de dificuldades no atendimento às mulheres vítimas de violência sexual. Sem esquecer que cerca de trezentas mil mulheres participaram, direta ou indiretamente, de conferências locais e estaduais em preparação para a IV Conferência Nacional de Políticas Públicas para Mulheres, convocada pelo governo federal e programada para acontecer em maio de 2016, em Brasília. 
A essa altura, porém, a conspiração contra o Governo Dilma já fervilhava. Respondendo a essas pressões, em outubro de 2015, a Presidenta eleita procedeu a uma reforma dos ministérios, rebaixando a Secretaria de Políticas para Mulheres $e$ incorporando-a ao então recém-criado Ministério das Mulheres, da Igualdade Racial e dos Direitos Humanos (MMIRDH), unindo a Secretaria de Políticas de Promoção da Igualdade Racial, a Secretaria de Direitos Humanos, e a Secretaria de Políticas para as Mulheres.

Recusou-se, porém, a acatar as manobras do Presidente da Câmara dos Deputados, Eduardo Cunha (hoje, supostamente preso por corrupção) que, em retaliação, aceitou, em 2 de dezembro de 2015, a denúncia do PSDB contra a Presidenta por crime de responsabilidade por pedaladas fiscais. Em 12 de maio de 2016, a Câmara federal votou pelo afastamento da Presidenta e, em 31 de agosto de 2016, o impeachment foi consolidado pela maioria do Senado (Bittencourt, 2017). ${ }^{14}$

Vale ressaltar que um dos últimos atos públicos da Presidenta Dilma foi em 10 de maio, na abertura da IV CNPM, quando declarou: "Eu não estou cansada de lutar, estou cansada dos desleais e dos traidores. Mas esse cansaço impulsiona a mim a lutar ainda mais" (Dilma..., 2016). Dois dias depois ela seria afastada, com a votação acontecendo bem ao final da IV CNPM, tendo grande parte das participantes caminhado em marcha para o Congresso Nacional em defesa da Presidenta, sendo recebidas por sprays de pimenta lançados pela Polícia Legislativa que montara um cerco nas proximidades do Congresso, revistando $e$ agredindo quem se aproximasse.

Que se tratava de um golpe de Estado ficou constatado quando, tão logo o vice-presidente Michel Temer assumiu o governo, como interino, o Congresso votou a favor de um projeto

\footnotetext{
${ }^{14}$ Recentemente, por meio de delações de grandes empresários, tornou-se público o fato de que esses votos para o afastamento e o impeachment da Presidenta Dilma foram comprados com mais de um milhão de reais em propinas [https://www.revistaforum.com.br/2017/10/15/impeachment-de-dilmafoi-comprado-diz-funaro/-acesso em: 20 jul. 2018]
} 
que descriminalizava pedaladas fiscais. E que questóes de gênero tinham um peso em todo esse processo, também ficou transparente quando, mais que depressa, Temer comandou o desmonte dos avanços dos governos do PT em prol das mulheres e dos direitos humanos, em geral, extinguindo, dentre outros órgãos, o MMIRDH e atribuindo suas funções ao Ministério da Justiça, que passou a se chamar oficialmente Ministério da Justiça e Cidadania (Rubim; Argolo, 2018).

Para assumir a SPM, agora um órgão sem expressão desse ministério, Temer nomeou a ex-Deputada Fátima Pelaes, do PMDB, outrora feminista e defensora dos direitos sexuais $e$ reprodutivos das mulheres e, atualmente, evangélica, militante do direito à vida "desde a concepção", tendo sido presidente da Frente Parlamentar Evangélica, que se coloca contra esses mesmos direitos (Melo, 2016). Ademais, contrariando o princípio de Estado laico da nossa Constituição, a Secretária Fátima Pelaes, junto à nova equipe que trouxe para a secretaria, passou a realizar sessões de cultos evangélicos na sede do órgão em Brasilia (Melo; Truffi, 2017).

Embora supostamente defensora de políticas de enfrentamento à violência contra mulheres, a nova secretária se posicionou a favor do projeto que extinguia os procedimentos profiláticos para vítimas de violência, permitindo, ainda, cortes substanciais no orçamento dos programas da secretaria, inclusive um corte de mais de $74 \%$ do orçamento para o "Atendimento às Mulheres em Situação de Violência” (Humberto..., 2016).

Junte-se a isso o fato da política internacional do Brasil na ONU ter sofrido grandes mudanças com a nomeação, primeiro, do Senador José Serra (PSDB) e, depois, do Senador Aloysio Nunes (PSDB), como Ministros das Relações Exteriores, ambos comandando posicionamentos que contrariam a luta pelos direitos humanos, inclusive das mulheres, no plano internacional. Em especial, o Itamarati agora se afasta da sociedade civil, a exemplo do que ocorreu em relação ao Relatório Nacional Voluntário para a Agenda 2030. As organizações não governamentais foram impedidas de participar da construção do documento, elaborando 
um relatório paralelo, em que demonstraram que o relatório oficial se caracterizou pela "manipulação de dados, contradições e a falta de indicadores, que ainda devem ser criados pelo governo federal" (Gomes, 2017).

Tudo isso tem se traduzido em um grande retrocesso no tocante aos direitos humanos das mulheres, a começar como o plano político. Conforme ressaltou a ex-Ministra Eleonora Menicucci em artigo recente:

Esse retrocesso, no plano político, é representado, por exemplo, pelo número irrisório de ministras (apenas duas em 27 ministérios). E no desmonte de programas que garantiriam a emancipação $e$ a igualdade de gênero. No aspecto referente à mulher na sociedade, o símbolo é a exaltação da primeira dama como o exemplo de mulher "bela, recatada e do lar", em clara oposição à imagem da presidenta Dilma (2018:72).

Esse retrocesso tem se verificado também no tocante à questão do enfrentamento à violência contra as mulheres, apesar de um discurso de apoio a essa luta. De fato, embora o Itamaraty tenha se comprometido a defender a questão da "[...] sensibilização para o enfrentamento à violência contra mulheres e meninas no meio rural e os problemas e desafios para o desenvolvimento de políticas que assegurem às mulheres o direito humano a uma vida sem violência [...]" nas reuniões da $62^{\mathrm{a}}$ sessão da CSW (Delegação..., 2018), o governo federal continua a cortar brutalmente verbas destinadas justamente a esse fim. $\mathrm{O}$ que se constata, na verdade, é um processo de "[...] desmonte dos programas e ações de enfrentamento da violência contra a mulher no Brasil", que caminha a passos largos (Enfrentamento..., 2017).

\section{Conclusão: $\mathrm{O}$ que se pode esperar?}

Ao longo deste trabalho, procurei demonstrar que a incorporação de uma perspectiva de equidade de gênero nos discursos e políticas sobre desenvolvimento resultou de um longo 
processo de negociação por parte dos movimentos feministas, com destaque para atuação dos feminismos brasileiros, sobretudo a partir dos anos 1990. Nas arenas da ONU, essa atuação se deu por meio de uma aproximação bastante profícua e produtiva dos feminismos com a representação brasileira, intermediada, desde o Governo Lula, pela SPM. Essa aproximação garantiu a liderança do Brasil nas conferências de Beijing e Beijing+, assegurando que os princípios fundamentais da Plataforma de Ação fossem mantidos.

Todavia, o golpe contra o Governo Dilma colocou no poder um governo retrógado no tocante aos direitos humanos, que, por sua vez, nomeou para a SPM uma liderança religiosa fundamentalista, cujas posturas se afastam radicalmente das que vêm caracterizando a atuação do Brasil nos espaços da ONU voltados para os direitos das mulheres. Nessas condições, dificilmente o Brasil poderá manter sua liderança, o que, certamente, será uma grande perda para os movimentos feministas e de mulheres para muito além de nossas fronteiras.

\section{Referências bibliográficas}

AlVAREZ, Sonia. A "Globalização" dos Feminismos Latino-Americanos. In: Alvarez, Sonia; Dagnino, Evelina; Escobar, Arturo (org.). Cultura e Política nos Movimentos Sociais Latino-Americanos. Belo Horizonte, Ed. UFMG, 2000, pp.383-426.

. Para além da sociedade civil: reflexões sobre o campo feminista. cadernos pagu (43), Campinas-SP, Núcleo de Estudos de GêneroPagu/Unicamp, 2014, pp.13-56.

et alii. Encountering Latin American and Caribbean Feminisms. Signs 28(2), 2003, pp.537-580.

ALVES, José Eustáquio; CORRÊA, Sônia. Demografia e ideologia: trajetos históricos e os desafios do Cairo +10 . Revista Brasileira de Estudos Populacionais vol. 20, $\mathrm{n}^{\circ}$ 2, Campinas, 2003, pp.129-156.

Antrobus, Peggy. The Global Women's Movement: Origins, Issues, and Strategies. London, Zed Books, 2004. 
Baden, Sally; Goetz, Anne-Marie. Who Needs [Sex] When You Can Have [Gender]. Feminist Review (56), 1997, pp.3-25.

BEnERÍA, Lourdes. Gender, Development and Globalization. Economics as if all people mattered. New York, Routledge, 2003.

BITTENCOURT, Julinho. "Impeachment de Dilma foi comprado", diz Funaro. Revista Fórum, Política, 15 out. 2017 [https://www.revistaforum.com.br/impeachment-de-dilma-foicomprado-diz-funaro/ - acesso em: 20 jul. 2018].

BoseruP, Ester. Woman's Role in Economic Development. New York, St. Martin's Press, 1970.

BRICHTA, Daniella; VIOTTI, Maria Luiza. Nações Unidas: uma perspectiva de gênero. Mundo Afora: Políticas de promoção da igualdade de gênero ${ }^{\circ}$ 7, Brasília, Ministério das Relações Exteriores, junho, 2011, pp.115-120.

BRUCE, Margaret K. Personal Notes on an Important Anniversary. United Nations Chronicle vol. XXXV, n 4, New York, 1998,pp.72-85.

Connelly, M. Patricia; MaCdOnAld, Mary; PARPART, Jane L. Feminism and Development. In: PARPART, J.L.; ConNelly; M.P.; BarRiteAu, V.E. (ed.). Theoretical Perspectives on Gender and Development. Ottawa: IDRC, 2000, pp.51-160.

CORNWALl, Andrea. Revisiting the "Gender Agenda". IDS Bulletin vol. 38, no 2, 2007, pp.69-79.

CORNWALL, Andrea; HARRISON, Elizabeth; WHITEHEAD, Ann. "Introduction: feminisms in development: contradictions, contestations and challenges". In:__. Feminisms in Development: contradictions, contestations \& challenges. London, Zed Books, 2007, pp.1-17.

DELEGAÇÃO brasileira pautará diversidade, enfrentamento à violência e trabalho para rurais na Comissão da ONU sobre a situação das mulheres a partir desta $2^{\mathrm{a}}$ Feira. ONU Mulheres, Brasil, 12/03/2018 [http://www.Onumulheres.Org.Br/Noticias/Delegacao-BrasileiraPautara-Diversidade-Enfrentamento-A-Violencia-E-Trabalho-ParaRurais-Na-Comissao-Da-Onu-Sobre-A-Situacao-Das-Mulheres-APartir-Desta-2a-Feira/ - acesso em: 20 jul. 2018]. 
DiLMA: não estou cansada de lutar, estou cansada dos desleais e dos traidores. Época Negócios, 10 de maio de 2016 [https://epocanegocios.globo.com/Brasil/noticia/2016/05/epocanegocios-dilma-nao-estou-cansada-de-lutar-estou-cansada-dosdesleais-e-dos-traidores.html - acesso em: 20 jul. 2017].

ENFRENTAMENTO da violência contra as mulheres: o que esperar e até quando esperar? Sindicato dos Servidores Públicos Municipais de Curitiba SISMUC, Formação, 04/10/2017 [http://sismuc.org.br/noticias/13/formacao/6387/enfrentamento-daviolencia-contra-as-mulheres-o-que-esperar-e-ate-quando-esperar? acesso em: 20 jul. 2018].

FRANCO, Jean. Deponer a El Vaticano. el proyecto secular del feminismo. Debate Feminista, vol. 27, 2003, pp.28-44.

FRIEDMAN, Elisabeth Jay. Seeking Rights from the Left: Gender and Sexuality in Latin American. In: BASU A. (org.). Women's Movements in the Global Era. The Power of Local Feminisms. Boulder, Colorado, Westview Press, 2010, pp.285-314.

GARCíA PRINCE, Evangelina. Beijing+15: Antesala de una Va Conferencia Mundial de las Mujeres? Perspectivas y Ajustes Necesarios, Beijing+ 15:Miradas desde el Feminismo. III Tercera Edicion de la Escuela del Pensamiento Feminista, Toledo, 2010.

GOETZ, Anne-Mariee; SANDLER, Joanne. SWApping gender: from crosscutting obscurity to sectoral security?. In: CORNWALL, Andrea; HARRISON, Elisabeth; WHITEHEAD, Ann (org.). Feminisms in Development: contradictions, contestations \& challenges. London, Zed Books, 2007, pp.161-173.

GOMES, Rodrigo. Após dois anos, Brasil nada fez por objetivos tratados na ONU. Rede Brasil Atual, 25 de setembro de 2017 [https://www.redebrasilatual.com.br/politica/2017/09/apos-dois-anosbrasil-nao-realizou-qualquer-acao-para-alcancar-objetivos-da-onu acesso em: 10 jan. 2018].

GOULART, Linda. Na comissão sobre a situação das mulheres, Brasil pede foco no futuro, 16 March [www.onumulheres.org.br/noticias/nacomissaosobre-a-situacao-das-mulheres-brasil-pede-focono-futuro acesso em: 10 maio 2015]. 
HADDAD-GuARNIERI, Tathiana. Os Direitos das mulheres no contexto internacional: da criação da ONU (1945) à Conferência de Beijing (1995). Revista Eletrônica da Faculdade Metodista Granbery n ${ }^{\circ} 8$, jan/jun 2010.

HADDAD, Tathiana. Diplomacia Pública: a política externa brasileira e as ONGs na Conferência de Beijing (1995). Dissertação (Mestrado em Relações Internacionais), PUC, Rio de Janeiro, 2007.

Harcourt, Wendy (org.). The Palgrave Handbook of Gender and Development: Critical Engagements in Feminist Theory and Practice. London, Palgrave Macmillan, 2016.

HUMBERTO critica corte no orçamento para políticas de proteção à mulher. Senador HC - Senador Humberto Costa 2015, 5 de dezembro de 2016 [http://www.senadorhumberto.com.br/tag/orcamento-para-oatendimento-as-mulheres-em-situacao-de-violencia/ - acesso em: 20 jul. 2017].

JAIN, Devaki. Women, Development, and the UN: A Sixty-Year Quest for Equality and Justice. Bloomington, Indiana University Press, 2005.

JAIN, Devaki; Elson, Diane (org.). Harvesting Feminist Knowledge for Public Policy. Rebuilding Progress. Delhi, India, SAGE Publications, 2011.

KABEER, Naila. Reversed Realities: Gender Hierarchies in Development Thought. London, Verso, 1994.

KANDIYOTI, Denise. Bargaining with Patriarchy. Gender and Society vol. 2, n 3, 1988, pp.274-290.

LiBARDONI, Marlene. Avaliação dos Processos de Negociação, Diálogo e Colaboração entre Governo e ONGs nos Processos de Beijing e PósBeijing na América Latina e Caribe - Sub-Região Brasil, Brasília. Fórum de ONGs da América Latina e Caribe com o Apoio do Fundo de Desenvolvimento das Nações Unidas para a Mulher e o Fundo das Nações Unidas Para a Criança, 1996.

MACHADO, Lia. Confrontos Políticos e Desafios Intelectuais. Revista Estudos Feministas vol. 3, n 2, 1995, pp.414-426.

MARCHAND, Marianne; PARPART, Jane (org.). Feminism/ Postmodernism/ Development. London, Routledge, 1995. 
MELO, Débora. No governo Temer, Secretaria das Mulheres ganha viés policial. Carta Capital, Política, 04/06/2016 [https://www.cartacapital.com.br/politica/sob-temer-fatima-pelaes-davies-policial-a-politicas-para-mulheres - acesso em: 20 jul. 2017].

MElO, Débora; TRUFFI, Renan. Secretária das Mulheres de Temer faz culto evangélico em gabinete. Carta Capital, Política, 29/03/2017 [https://www.cartacapital.com.br/politica/secretaria-das-mulheres-detemer-faz-culto-evangelico-em-gabinete - acesso em: 20 jul. 2017].

MENDOZA, Brenny. Coloniality of Gender and Power: From Postcoloniality to Decoloniality. In: DISCH, Lisa; HAWKESWORTH, Mary (org.). The Oxford Handbook of Feminist Theory, Oxford: Oxford University Press, 2016, pp.100-121.

MogHADAM, Valentine M. Globalizing Women. Transnational Feminist Networks. Baltimore, The John Hopkins University Press, 2005.

MOLYNEUX, Maxine. The chimera of success: gender ennui and the changed international policy environment. In: CORNWALL, Andrea; HARRISON, Elizabeth; WHITEHEAD, Ann (org.). Feminisms in Development: contradictions, contestations \& challenges. London, Zed Books, 2007, pp.227-240.

Moraes, Maria Lygia. Mulheres em Movimento. São Paulo, Conselho Estadual da Condição Feminina/ Nobel, 1985.

Nicodemos, Marcela. As Nações Unidas e a Promoção do Direito da Mulher: Retórica ou Realidade? Monografia apresentada ao IRBHXLVIII CAE, 2005.

ORGANIZAÇÃO das Nações Unidas -- https://nacoesunidas.org/carta/

ORGANIZAÇÃO das Nações Unidas. Relatório da Conferência Internacional sobre População e Desenvolvimento (CIPD). Cairo, Egito, 5 a 13 de setembro de 1994 [http://www.200.130.7.5/spmu/portal_pr/eventos internacionais/onu/ Relat\%C3\%B3rio\%20Cairo.pdf - acesso em: 20 jul. 2017].

PEARSON, Ruth; JACKSON, Cecile. Interrogating Development: Feminism, Gender and Policy. In: JACKSON, Cecile; PEARSON, Ruth (ed.). Feminist Visions of Development. London, Routledge, 1998, pp.1-16.

PINTO, Céli. Uma história do feminismo no Brasil. São Paulo, Fundação Perseu Abramo, 2003. 
PITANGUY, Jacqueline. Bridging the local and the global: feminism in Brazil and the international human rights agenda. Social Research, Fall 2002 [http://findarticles.com/p/articles/mi_m2267/is_3 69/ai_94227142 acesso em: $10 \mathrm{dez} 2008$ ].

RAI, Shirin. The Gender Politics of Development. London, Zed Books, 2008.

. The history of international development: concepts and contexts. In: VisvanATHAN, N. et alii (ed.). The Women, Gender and Development Reader. 2 ed., London, Zed Books, 2011, pp.14-21.

RAZAvi, Shahra; MILler, Carol. From WID to GAD: Conceptual Shifts in the Women in Development Discourse (UNRISD Occasional Paper for the Fourth World Conference on Women, Beijing 1995) OP 1, Geneva, UNRISD/UNDP, February, 1995.

RIBEIRO, Matilde. Mulheres Negras Brasileiras: de Bertioga à Beijing. Revista Estudos Feministas vol. 3, n 2, 1995, pp.446-457.

RubiM, Linda; ARgolo, Fernanda (org.). O Golpe na Perspectiva de Gênero. Salvador, EDUFBA, 2018.

SAFFIOTI, Heleieth. Enfim, sós: Brasil rumo a Pequim. Revista Estudos Feministas vol.3, nº 1, 1995, pp.198-202.

SANT'AnNA, Wânia. A Caminho de Beijing+5, Proposta 84/85, 2000.

SARDENBERG, Cecilia. Brazilian Feminisms in Global Spaces: Beijing and Beijing+20. IDS Bulletin vol. 46, Brighton, UK, 2015, pp.115-122.

. Migrações Perigosas: As (Des)Aventuras Semânticas do Conceito de Gênero nos Projetos e Políticas para Mulheres no Brasil. In: GONÇALVES, E. et alii (org.). Iguais? Gênero, trabalho e lutas sociais. Goiânia, PUC Goiás, 2014, pp.19-48.

. Liberal vs Liberating Empowerment: Conceptualising Women's Empowerment from a Latin American Feminist Perspective. Brighton, Institute of Development Studies: Pathways of Women's Empowerment, Pathways Working Paper 7, 2009.

SARdenberG, Cecilia; CostA, Ana Alice. Feminisms in Contemporary Brazil: Advancements, Shortcomings, and Challenges. In: BASU, A. 
(ed.). Women's Movements in a Global Era: The Power of Local Feminisms. Boulder CO, Westview Press, 2010, pp.255-284.

Schumaher, Maria Aparecida. América Latina mais integrada. Revista Estudos Feministas vol. 3, n² 2, 1995, pp.427-433.

SEn, Gita; Grown, Caren. Development, Crises, and Alternative Visions: Third World Women's Perspectives. New York, Monthly Review Press, 1987.

SOARES, Vera. O contraditório e ambíguo caminho para Beijing. Revista Estudos Feministas, vol. 3, n 1, 1995, pp.180-190.

SolHET, Rachel. O feminismo tático de Bertha Lutz. Florianópolis, Editora das Mulheres, 2006.

SternbaCh, N.; Navarro-Aranguren, M.; Chuchryk, P.; Alvarez, S. Feminisms in Latin America: From Bogota to San Bernardo. Signs, 17 (2), 1992, pp.393-434.

TinkER, Irene; BrAmSEn, Mary (ed.). Women and World Development. AAAS, Overseas Development Council, 1976.

TRUMAN, Harry S. Inaugural address. In: COPELAND, Lewis et alii (ed.). The World's great speeches. New York, Courier Dover Publications, 1999, pp.589-591.

UNITED Nations. Charter of the United Nations and Statute of the International Court of Justice. San Francisco, 1945.

. The Population and Development - Programme of Action adopted at the International Conference on Population and Develpment, Cairo 5-13 September, 1994. New York, Department of Public Information, 1995.

. The Beijing Declaration and the Plataform for Action. New York, Department of Public Information, 1996.

. A global Agenda - Issues before the 52nd General Assembly of the United Nations. New York, UNA-USA, 1998.

VARGAS, Virginia. Constructing New Paradigms for Global Democracy: The Contribution of Feminisms. In: MAIER, Elizabeth; LEBON, Nathalie (ed.). Women's Activism in Latin American and the Caribbean. New Brunswick, N.J., Rutgers University Press, 2010. 
cadernos pagu (52), 2018:e185201 Negociando gênero em desenvolvimento: os feminismos brasileiros em destaque

WhITEHEAD, Ann. Some Preliminary Notes on the Subordination of Women, IDS Bulletin 10, 1979, pp.10-13.

YounG, Kate; Wolkowitz, Carol; MccullagH, Robin. Of Marriage and the Market: Women's Subordination Internationally and its Lessons. London, Routledge and Kegan Paul, 1980.

- Planning Development with Women: Making a World of Difference. London, Macmillan, 1993. 